\title{
Valorization of Brick and Glass CDWs for the Development of Geopolymers Containing More Than $80 \%$ of Wastes
}

\author{
Dimitris Kioupis $\mathbb{D}^{\mathbb{D}}$, Aggeliki Skaropoulou, Sotirios Tsivilis and Glikeria Kakali * \\ School of Chemical Engineering, National Technical University of Athens, 15773 Athens, Greece; \\ dkioupis@central.ntua.gr (D.K.); agskarop@central.ntua.gr (A.S.); stsiv@central.ntua.gr (S.T.) \\ * Correspondence: kakali@central.ntua.gr; Tel.: +30-2107723270
}

Received: 19 June 2020; Accepted: 27 July 2020; Published: 29 July 2020

check for updates

\begin{abstract}
One of the areas of priority in a circular economy, regarding waste management, regards the valorization of construction and demolition wastes (CDW). This study suggests the synthesis of geopolymeric binders based almost entirely on construction and demolition wastes. Ceramic waste was used as the aluminosilicate precursor of the geopolymer synthesis, while glass waste was applied in the preparation of the activation solution. A fractional experimental design defined the optimum synthesis parameters, based on compressive strength values. The final products were characterized by means of X-Ray Diffraction (XRD), Fourier-Transform Infrared Spectroscopy (FTIR) and Scanning Electron Microscopy (SEM). The glass waste was appropriately processed in order to prepare the activation solution for the geopolymerization of brick waste. In this work, CDW-based geopolymers were produced with a compressive strength in the range 10-44 MPa. The developed products contained $80-90 \mathrm{wt} . \%$ CDWs, depending on the method of activator preparation.
\end{abstract}

Keywords: geopolymer; CDW; waste brick; waste glass; compressive strength; characterization

\section{Introduction}

Nowadays, there is an imperative need to transform our economies into more sustainable ones. The model of the "linear economy", which has been adopted globally up till now, is based on the "make-take-dispose" concept, whereby natural materials and resources are transformed into products that our societies use until they are finally discarded as wastes. However, the scarcity of natural resources, the high energy demand of production processes and the high rate of waste landfilling indicate that this type of economy is coming to an end. For this reason, a new economic system, called "circular economy" [1], has emerged, aiming to preserve natural resources for as long as possible, by keeping the generation of waste to its minimum [2]. In other words, the goal of such economies is to create closed-loop systems by reusing, recycling, sharing, repairing and remanufacturing, and therefore to minimize the use of natural resources and the generation of waste, pollution and greenhouse gas emissions [3].

Speaking of the construction sector, Portland cement is the most widespread material, used as the main component of concrete or other cementitious materials. It is well established that Portland cement production is one of the most energy-intensive and non-environmentally friendly production processes, since it requires significant consumptions of natural resources in clinker manufacturing and rotary kiln operation. In numerical terms, $6-7 \%$ of the total $\mathrm{CO}_{2}$ emissions are attributed to the cement industry. Furthermore, 1.7 tons of natural materials are consumed and 0.8 tons of $\mathrm{CO}_{2}$ are emitted for the production of only 1 ton of cement [4-6].

From the circular economy point of view, efforts to find alternatives to Portland cement are necessary. In recent years, great emphasis has been placed on building materials called geopolymeric 
or alkali-activated binders. Purdon [7], V. Glukhovsky [8], J. Davidovits [9] and J.S.J. Van Deventer [10] were the first to address this field, and developed the first alkali-activated cements. These materials exhibit competitive properties compared to conventional building materials, such as rapid strength development and resistance to corrosive environments. The geopolymerization process involves the reaction of an aluminosilicate raw material and a silicate solution in an alkaline medium, and then the curing of the mixture under mild conditions. The above process has significant environmental benefits, such as the utilization of industrial by-products and wastes as raw materials, natural resource and energy savings, and the reduction of $\mathrm{CO}_{2}$ emissions [11,12].

In addition to the unsustainable cement products, the construction sector accounts also for one of the biggest waste sources globally, namely, construction and demolition wastes (CDWs). These wastes are mostly generated by construction, renovation, repair or demolition activities, and often contain bulky and heavy materials including concrete, wood, asphalt, gypsum, metals, bricks, glass, plastics, etc. Most of these wastes are not reused/recycled, and are mainly deposited in the environment, causing disposal problems. According to Eurostat, the construction sector in the EU-28 produced 920 million tons of waste, representing 36\% of the total waste generation in the year 2016 [13]. According to the binding legislation set by the EU, 70\% by weight of non-hazardous CDW must be reused, recycled or recovered by the year 2020 [14]. A major part of these wastes (30\%) is of ceramic origin (bricks, tiles, etc.), and their structure is characterized by a high degree of disorder, since they have been treated in high temperatures at the production stage. From this perspective, aluminosilicate-based CDWs can be reused as precursors for the preparation of high added value materials via geopolymerization [15-19]. Furthermore, CDW glass can be applied in the preparation of the activation solution, due to its high $\mathrm{Si}$ and Na amorphous content [20-24]. Conventionally, the preparation of the activation solution involves the use of commercial alkali silicates, the production of which is significantly energy-intensive [25]. Thus, the development of glass waste activation solution will provide a significant reduction in the environmental footprint of geopolymerization.

This study deals with the development of a green building material based almost entirely on construction and demolition wastes through the geopolymerization process. The research was carried out in three stages:

1. Synthesis optimization of CDW-based geopolymers, using the conventional activation solution. In this stage, the assessment of the effects of synthesis factors, such as $\mathrm{Si} / \mathrm{Al}, \mathrm{R} / \mathrm{Al}$ (R: $\mathrm{Na}$ or $\mathrm{K}$ ) and $\mathrm{Na} / \mathrm{Na}+\mathrm{K}$ molar ratios, on the microstructures and mechanical properties of the products, was performed;

2. Development of an activation solution based on glass waste. In this stage, dissolution studies of the glass waste were performed, and the effect of parameters such as the alkalinity of the extracting solution, the temperature and the duration of the dissolution were assessed;

3. Testing of the efficiency of the glass waste solutions when used as activators for CDW-based geopolymers.

It must be noted that the thorough study of alkaline glass dissolution was not within the scope of this work, as it has been extensively studied [26-29]. The target of this work was to obtain a glass waste solution, under relatively mild conditions, that can be used for the geopolymerization of CDWs.

\section{Materials and Methods}

\subsection{Raw Materials}

The brick precursor used in this study originates from bricks rejected at the industrial site because they do not conform to the quality control standards of the brick industry. This type of waste belongs also to CDWs, and its composition is very close to that of waste originating from construction and demolition activities. The utilized glass waste is a typical glass used in the fabrication of windowpanes. Brick and glass wastes were pulverized (pro-pilot plant ball mill, $\mathrm{L}=480 \mathrm{~mm}, \mathrm{D}=380 \mathrm{~mm}$ ) in order to 
enhance their reactivity. Table 1 and Figure 1 present the fineness characteristics of the waste materials. In the case of glass waste, only the fraction below $56 \mu \mathrm{m}$ was used for the preparation of sodium silicate solutions.

Table 1. Fineness characteristics of CDW brick and glass.

\begin{tabular}{lcc}
\hline Fraction & Brick & Glass \\
\hline $\mathrm{d}_{90}(\mu \mathrm{m})$ & 71.4 & 169.1 \\
$\mathrm{~d}_{50}(\mu \mathrm{m})$ & 13.7 & 50.0 \\
\hline
\end{tabular}

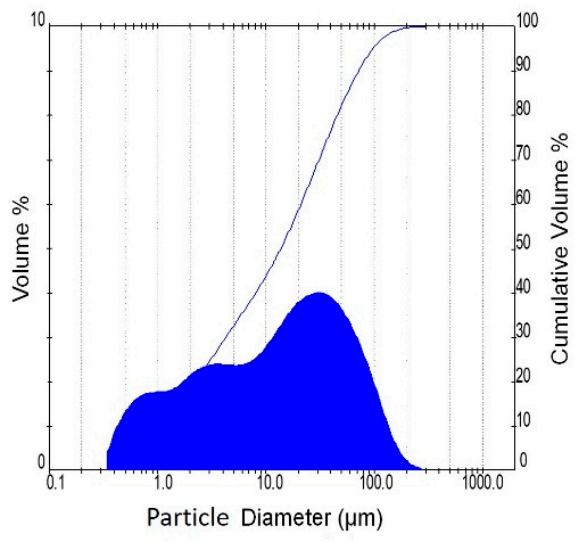

(a)

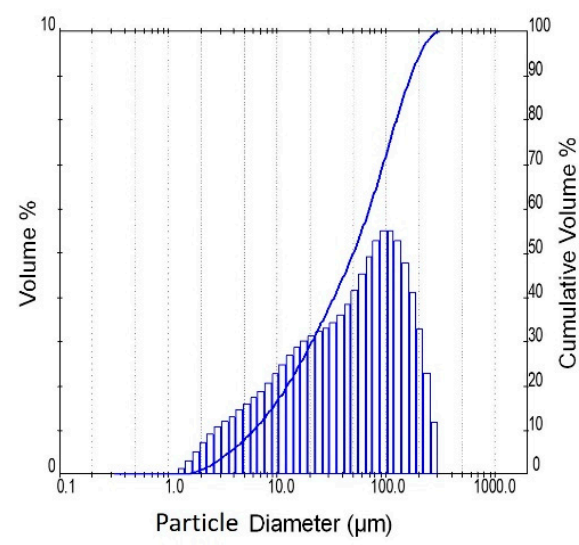

(b)

Figure 1. Particle size distribution of brick (a) and glass (b).

The chemical composition of waste materials was determined by means of X-ray fluorescence spectroscopy (Table 2). The selected brick waste is a promising aluminosilicate precursor since it contains sufficient amounts of $\mathrm{SiO}_{2}$ and $\mathrm{Al}_{2} \mathrm{O}_{3}$ that are necessary for the reactions of geopolymerization. Furthermore, glass waste according to its chemical composition can be classified as a soda-lime glass.

Table 2. Chemical composition of the CDW precursors $(\% \mathrm{w} / \mathrm{w})$.

\begin{tabular}{|c|c|c|c|c|c|c|c|c|c|c|c|c|}
\hline Waste & $\mathrm{SiO}_{2}$ & $\mathrm{Al}_{2} \mathrm{O}_{3}$ & $\mathrm{Fe}_{2} \mathrm{O}_{3}$ & $\mathrm{CaO}$ & $\mathrm{MgO}$ & $\mathrm{K}_{2} \mathrm{O}$ & $\mathrm{Na}_{2} \mathrm{O}$ & $\mathrm{SO}_{3}$ & $\mathrm{TiO}_{2}$ & $\mathrm{P}_{2} \mathrm{O}_{5}$ & $\mathrm{Cl}$ & L.O.I. * \\
\hline Brick & 61.02 & 18.85 & 7.87 & 1.73 & 3.03 & 3.40 & 1.27 & 0.26 & 0.89 & 0.17 & 0.02 & 1.49 \\
\hline Glass & 71.35 & - & - & 10.10 & 3.80 & - & 14.28 & - & - & - & - & 0.47 \\
\hline
\end{tabular}

XRD analysis (Figure 2) revealed that brick waste possesses the typical mineral composition of a calcined-clay brick. The predominant mineral phase is quartz, along with small amounts of hematite and muscovite. The amorphous content of the brick waste was calculated through quantitative XRD analysis by DIFFRAC.TOPAS V5.0 software, and it was found to be $43.9 \% \mathrm{w} / \mathrm{w}$. Glass waste is mainly amorphous $(74.7 \%)$, with a broad hump in the range $15-35^{\circ}$, indicating the vitrified silicate phases. 


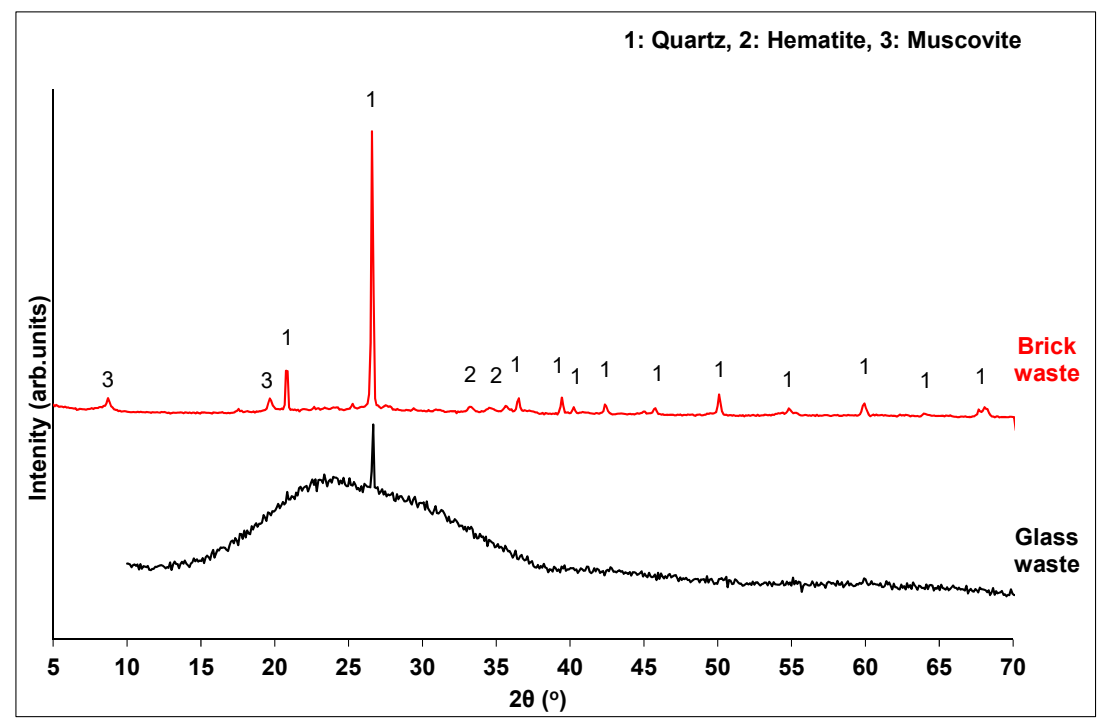

Figure 2. XRD pattern of waste precursors.

\subsection{Geopolymer Synthesis}

The activation solution used in this study was either based on commercial chemicals or derived from the CDW glass dissolution. Concerning the preparation of the conventional activation solution, the appropriate amounts of alkali hydroxides $(\mathrm{NaOH} \geq 98.0 \%$, CAS No. $1310-73-2$ and $\mathrm{KOH} \geq 85.0 \%$, CAS No.1310-58-3) were dissolved in water, and then soluble $\mathrm{Si}$ in the form of $\mathrm{SiO}_{2}$ solution (silica colloidal dispersion in water, 50\% w/w, CAS: 7631-86-9) was added. The solutions were stirred for $1 \mathrm{~h}$ prior to use. Then, the waste brick powder and the alkali silicate activator were mixed (standard mortar mixer: Controls 65-L0005) until a homogenous slurry was formed. The prepared pastes were casted in $50 \mathrm{~mm} \times 50 \mathrm{~mm} \times 50 \mathrm{~mm}$ cubic molds and compacted on a vibrating table. The specimens were sealed with plastic film to prevent drastic moisture loss, cured at $80^{\circ} \mathrm{C}$ for 3 days and then were kept in plastic bags at room temperature until mechanical testing was performed.

Due to the complexity of the geopolymerization process, the application of a multifactorial design of experiments (DoE), called the Taguchi method [30], was selected for the optimization of geopolymer synthesis. The major advantage of this DoE is that it can fully describe the examined process or product by conducting a minimum number of experiments, and thus saves valuable time and cost. In this study, Minitab ${ }^{\mathrm{TM}}$ software was used to design the experiments and statistically analyze the results.

In this study, the DoE target was to maximize the compressive strength of the produced geopolymers. Then, the factors affecting the geopolymer synthesis, as well as their value range, were defined. The selected factors were the following: i) the overall amount of Si involved in the geopolymerization process originating from both brick precursor and activation solution, expressed as the Si/Al molar ratio; ii) the alkalinity of the activation solutions expressed as alkali to aluminum molar ratio (R/Al, $\mathrm{R}: \mathrm{Na}$ or $\mathrm{K})$; and iii) the kind of alkali in the activation solution $(\mathrm{Na} / \mathrm{Na}+\mathrm{K})$. It is well established in the literature that these factors have a major effect on the geopolymeric synthesis [31-33]. The orthogonal array L16 was applied in the design of the experiments. This array involves the variation of the above factors at four levels, and keeps the number of the needed experiments to 16 , while a full factorial design requires the performance of 64 experiments in order to fully describe the same system. The various levels of the selected factors are presented in Table 3. The factor value range is determined by physical and chemical restrictions. 
Table 3. Selected factors and their variation range.

\begin{tabular}{ccccc}
\hline Factors & Level 1 & Level 2 & Level 3 & Level 4 \\
\hline $\mathrm{Si} / \mathrm{Al}$ & 2.75 & 3.00 & 3.25 & 3.50 \\
$\mathrm{R} / \mathrm{Al}$ & 0.50 & 0.75 & 1.00 & 1.25 \\
$\mathrm{Na} / \mathrm{Na}+\mathrm{K}$ & 0.00 & 0.35 & 0.70 & 1.00 \\
\hline
\end{tabular}

The analysis of the data obtained from the tests and the interpretation of the results was done through ANOVA (Analysis of Variance). The results are graphically illustrated and the percent contribution of each factor to the development of the compressive strength was exported. Finally, verification experiments were performed in order to confirm the results of the DoE. The application of fractional multifactorial DoE for the geopolymer synthesis is well described in previously published studies [34,35].

\subsection{Glass Waste Dissolution}

The glass waste was thermally treated in alkaline media in order to achieve high dissolution rates. The experiments performed are presented in Table 4. The dissolution of the glass was investigated through the study of the following parameters: (i) the content of sodium hydroxide in the extracting solution, denoted as $\mathrm{NaOH} / \mathrm{SiO}_{2}$ molar ratio (experiments GL2, GL3 and GL4); (ii) the water amount of the extracted solution, $\mathrm{H}_{2} \mathrm{O} / \mathrm{SiO}_{2}$ molar ratio (experiments GL4 and GL5); (iii) the temperature of the dissolution process (experiments GL1 and GL2); and (iv) the duration of the dissolution process (experiments GL5 and GL6). According to the literature, the aforementioned parameters are crucial to the glass dissolution $[22,36,37]$.

Table 4. Experiments on waste glass dissolution.

\begin{tabular}{cccccccc}
\hline Exp. & $\mathbf{T}\left({ }^{\circ} \mathbf{C}\right)$ & $\mathbf{t}(\mathbf{h})$ & $\mathbf{N a O H} / \mathbf{S i O}_{\mathbf{2}}$ & $\mathbf{H}_{\mathbf{2}} \mathbf{O} / \mathbf{S i O}_{\mathbf{2}}$ & Glass (g) & $\mathbf{N a O H}(\mathbf{g})$ & $\mathbf{H}_{\mathbf{2}} \mathbf{O}(\mathbf{g})$ \\
\hline GL1 & 100 & 24 & 4 & 23 & 10.28 & 19.34 & 50.00 \\
GL2 & 150 & 24 & 4 & 23 & 10.28 & 19.34 & 50.00 \\
GL3 & 150 & 24 & 2 & 23 & 10.28 & 9.67 & 50.00 \\
GL4 & 150 & 24 & 1 & 23 & 10.28 & 4.84 & 50.00 \\
GL5 & 150 & 24 & 1 & 9 & 27.27 & 13.07 & 50.00 \\
GL6 & 150 & 96 & 1 & 23 & 10.28 & 4.84 & 50.00 \\
\hline
\end{tabular}

Concerning the procedure that was followed, the CDW glass was milled and sieved to obtain a certain fineness (particle size $\leq 56 \mu \mathrm{m}$ ). Then, the appropriate amounts of CDW glass, sodium hydroxide and water (Table 4) were mixed and heated under stirring. At the end of each trial, the solutions were filtered in order to separate the liquid phase from the solid residue. The Si content in the solution was measured by means of ICP-OES, while the Na content was determined through titration with $1 \mathrm{M} \mathrm{HCl}$.

\subsection{Characterization Techniques}

The geopolymer specimens were tested under unconfined compression according to ASTM C 109 requirements (loading rate: $1.5 \mathrm{kN} / \mathrm{s}$ ) on a Toni-Technik uniaxial testing press. The compression tests were performed 7 days after the specimens' preparation. It has been found that at this age, oven-cured geopolymers have almost reached the maximum compressive strength [38]. In each experiment, three specimens were prepared and tested under compression. In cases where there was more than $\pm 10 \%$ variation from the mean value, the measurement was discarded and new specimens were prepared.

Mineralogical characterization of the CDW precursors and the final products was carried out by X-ray diffraction, using a Bruker D8 ADVANCE X-ray diffractometer (Bruker, Billerica, MA USA). The measuring conditions were the following: $2 \theta$ range $5-70^{\circ}$, step size $0.1^{\circ} / \mathrm{sec}$. The data were evaluated using Diffrac. Eva v3.1 software. 
FTIR measurements were performed on a Fourier Transform IR Spectrophotometer (Jasco 4200 Type A, Jasco, Easton, MD, USA). The FTIR spectra were obtained within a wavenumber range from 400 to $4000 \mathrm{~cm}^{-1}$ and resolution of $4 \mathrm{~cm}^{-1}$. The FTIR measurements were carried out by the KBr pellet technique. The pellets were prepared by pressing a mixture of the sample and dried $\mathrm{KBr}$ (sample: $\mathrm{KBr}$ equal to 1:200, approximately) at $7.5 \mathrm{t} / \mathrm{cm}^{2}$.

The final products' morphology and phase stoichiometry was examined by Scanning Electron Microscopy (SEM) on a JEOL JSM-5600 Microscope equipped with an OXFORD LINK ISIS 300 Energy Dispersive X-ray spectrometer (EDS). The samples examined were gold coated prior to the measurement.

The obtained solutions from the glass waste dissolution studies were diluted to $250 \mathrm{~mL}$ and the $\mathrm{Si}$ content was measured by means of ICP-OES by the use of a Prodigy-Teledyne, Leeman Labs atomic emission spectrometer with inductively coupled plasma.

\section{Results}

\subsection{Synthesis Optimization}

Table 5 presents the synthesis parameters, the compressive strength and the density of the geopolymers. The wide variation in the compressive strength values (20.3-43.7 MPa) indicates that the selected parameters have a significant effect on the development of the compressive strength. In the same table, the solid/liquid mass ratio within the starting mixtures is also shown. This ratio was adjusted in order to obtain the same paste workability in all samples.

Table 5. Synthesis parameters, compressive strength and density of the final products.

\begin{tabular}{ccccccccc}
\hline Sample * & Si/Al & R/Al * & $\begin{array}{c}\mathbf{N a} \text { / } \\
\mathbf{N a}+\mathbf{K} \ddagger\end{array}$ & $\begin{array}{c}\text { Solid/ } \\
\text { Liquid }\end{array}$ & $\begin{array}{c}\mathbf{S i O}_{2} / \\
\mathbf{R}_{\mathbf{2}} \mathbf{O} \ddagger\end{array}$ & $\begin{array}{c}\mathbf{H}_{\mathbf{2}} \mathbf{O} / \\
\mathbf{R}_{\mathbf{2}} \mathbf{O} \ddagger\end{array}$ & $\begin{array}{c}\text { Compressive } \\
\text { Strength } \\
\mathbf{( M P a})\end{array}$ & $\begin{array}{c}\text { Density } \\
\left(\mathbf{g} / \mathbf{c m}^{3} \mathbf{)}\right.\end{array}$ \\
\hline WBG_1 & 2.75 & 0.50 & 0.00 & 3.8 & 0.0 & 35 & $24.1 \pm 0.6$ & 1.72 \\
WBG_2 & 2.75 & 0.75 & 0.35 & 3.9 & 0.0 & 24 & $28.6 \pm 0.8$ & 1.91 \\
WBG_3 & 2.75 & 1.00 & 0.70 & 3.9 & 0.0 & 19 & $26.3 \pm 0.5$ & 2.01 \\
WBG_4 & 2.75 & 1.25 & 1.00 & 3.9 & 0.0 & 16 & $20.3 \pm 0.2$ & 1.92 \\
WBG_5 & 3.00 & 0.50 & 0.35 & 4.2 & 1.0 & 30 & $37.4 \pm 1.8$ & 1.84 \\
WBG_6 & 3.00 & 0.75 & 0.00 & 5.2 & 0.7 & 16 & $43.7 \pm 0.9$ & 2.03 \\
WBG_7 & 3.00 & 1.00 & 1.00 & 4.6 & 0.5 & 14 & $21.7 \pm 0.4$ & 1.83 \\
WBG_8 & 3.00 & 1.25 & 0.70 & 4.6 & 0.4 & 12 & $24.2 \pm 0.3$ & 1.94 \\
WBG_9 & 3.25 & 0.50 & 0.70 & 4.6 & 2.0 & 25 & $33.3 \pm 0.4$ & 2.03 \\
WBG_10 & 3.25 & 0.75 & 1.00 & 4.6 & 1.3 & 18 & $36.1 \pm 1.7$ & 2.03 \\
WBG_11 & 3.25 & 1.00 & 0.00 & 4.8 & 1.0 & 13 & $27.1 \pm 0.6$ & 2.05 \\
WBG_12 & 3.25 & 1.25 & 0.35 & 4.6 & 0.8 & 12 & $24.0 \pm 0.9$ & 2.01 \\
WBG_13 & 3.50 & 0.50 & 1.00 & 4.6 & 3.0 & 23 & $24.9 \pm 0.6$ & 1.88 \\
WBG_14 & 3.50 & 0.75 & 0.70 & 4.6 & 2.0 & 16 & $33.0 \pm 0.8$ & 1.99 \\
WBG_15 & 3.50 & 1.00 & 0.35 & 5.2 & 1.5 & 10 & $29.2 \pm 1.0$ & 2.00 \\
WBG_16 & 3.50 & 1.25 & 0.00 & 5.2 & 1.2 & 8 & $23.0 \pm 0.5$ & 2.00 \\
\hline
\end{tabular}

${ }^{*}$ WBG_x: Waste Brick Geopolymer_number of experiment. ${ }^{\dagger}$ refers to the starting mixtures (brick waste precursor and activation solution). $\ddagger$ refers to activation solution.

The data of Table 5 was processed through ANOVA statistical analysis, and the effect of the examined parameters on the compressive strength was plotted (Figure 3). Figure 3 also shows the contribution of each parameter to the development of the compressive strength. 


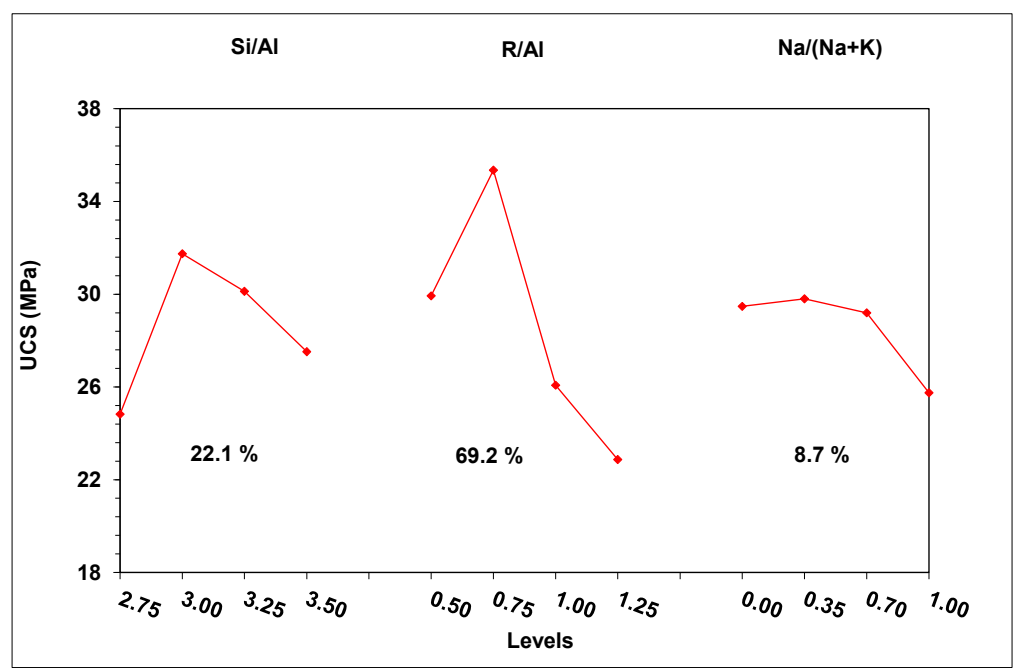

Figure 3. Effect of the studied factors on the development of compressive strength.

The factor with the major effect on compressive strength development is the alkalinity ratio (69.2\%). A limited amount of alkalis $(\mathrm{R} / \mathrm{Al}=0.50)$ resulted in decreased $\mathrm{pH}$ values in the activating solutions, and thus in a reduction in the dissolution of the brick waste precursor. Indeed, a decrease of R/Al from 1.25 to 0.5 led to a corresponding decrease of $\mathrm{pH}$ values from 14.26 to 11.65. The absence of adequate amounts of solubilized $\mathrm{Si}$ and $\mathrm{Al}$ ions in the system restricts the formation of the geopolymeric matrix, leading to products with poor mechanical behavior. Apart from that, the lack of alkaline ions may affect the participation of $\mathrm{Al}$ ions in the geopolymerization reactions, since each $\mathrm{Al}$ ion involved in the geopolymer network requires an alkaline ion for charge balance [39,40]. The presence of higher amounts of alkalis $(\mathrm{R} / \mathrm{Al}=0.75)$ during geopolymerization led to the formation of products with high structural integrity. However, in high concentrations $(\mathrm{R} / \mathrm{Al}=1.25)$, alkalis cannot be incorporated into the geopolymeric matrix, and react with the $\mathrm{CO}_{2}$ in the atmosphere, forming carbonates that degrade the mechanical performance of the geopolymeric matrix. In the literature, carbonate formation is also reported to negatively affect the development of the mechanical strength of geopolymers [35,41]. The XRD analysis of the white powder deposited on the specimens' surface confirmed the formation of carbonate phases. Figure 4 presents the XRD pattern of the white powder collected from the surface of WBG_4 (shown in Figure 5d).

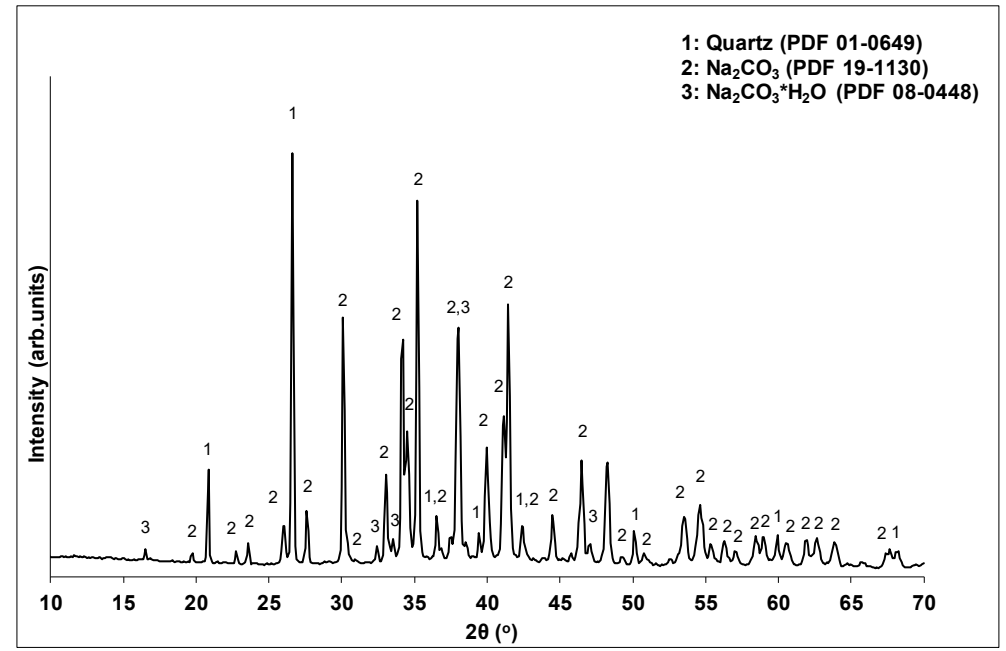

Figure 4. XRD pattern of depositions on the specimens' surface. 


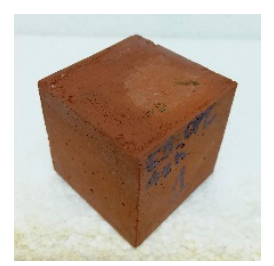

(a)

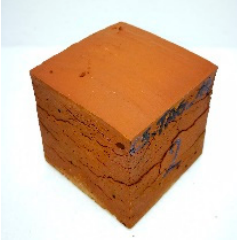

(c)

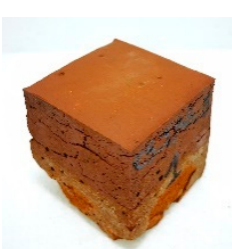

(b)

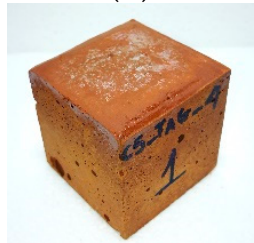

(d)

Figure 5. Photos of geopolymers: (a) optimum synthesis, (b) WBG_8, (c) WBG_14 and (d) WBG_4.

The $\mathrm{Si} / \mathrm{Al}$ molar ratio is the second most influential parameter (22.1\%). The introduction of extra silicon into the synthesis, through the activation solution, favors the preparation of geopolymeric products with enhanced mechanical performance. The extra silicon ions favor the formation of the geopolymer matrix by acting as nucleation points for the polycondensation reactions [39]. Further increases in the $\mathrm{Si}$ in the activation solution $(\mathrm{Si} / \mathrm{Al}>3.00)$ have a negative effect on strength development. It seems that excesses of silicon ions in the activation solution restrict the dissolution of the aluminosilicate precursor by shifting the dissolution reaction to the left.

The type of alkali ( $\mathrm{K}$ or $\mathrm{Na}$ ) makes a limited contribution to the mechanical strength development. Higher strength is achieved by using activation solutions rich in potassium ions $(\mathrm{Na} / \mathrm{Na}+\mathrm{K}=0.35)$, while the gradual substitution of potassium by sodium leads to strength reduction. The alkali species affect both the initial dissolution of the raw material and the polycondensation of the geopolymeric gel. In particular, the presence of smaller alkali ions, such as sodium, is proven to be more efficient with regard to aluminosilicate material dissolution, while potassium ions, which are heavier, favor the formation of disordered structures that positively affect the geopolymeric matrix formation $[39,40]$.

ANOVA analysis also defined the optimum combination of the parameters $(\mathrm{Si} / \mathrm{Al}=3.00, \mathrm{R} / \mathrm{Al}=0.75$ and $\mathrm{Na} / \mathrm{Na}+\mathrm{K}=0.35$ ) for achieving the maximum compressive strength. This strength was predicted to be $39.8 \pm 3.0 \mathrm{MPa}$ ( $95 \%$ confidence interval). The above conditions were applied for the preparation of specimens (confirmation test) in order to validate the predictions of the experimental designing model. The results showed that the measured strength falls within the predicted range (42.5 MPa), and thus confirms the validity of the applied DoE.

Due to the fact that the solubilization of glass waste took place with the use of sodium hydroxide solutions, a synthesis which contains only sodium hydroxide in its activation solution was used for comparison reasons. For that purpose, the synthesis with $\mathrm{Si} / \mathrm{Al}=3.00, \mathrm{R} / \mathrm{Al}=0.75$ and $\mathrm{Na} / \mathrm{Na}+\mathrm{K}=1$ was performed. The ANOVA analysis predicts a $35.7 \pm 3.0 \mathrm{MPa}$ for a $95 \%$ confidence interval. The preparation of this geopolymer led to specimens with compressive strengths in the vicinity of $32.9 \mathrm{MPa}$.

\subsection{Physicochemical Characterizations}

Figure 5 shows photos of selected geopolymer specimens. As is obvious, the geopolymers, prepared under optimum conditions, form compact and well-shaped specimens (Figure 5a). Low quality products, exhibiting increased porosity, cracking and carbonation phenomena, were obtained in the cases of low or high alkalinity, or where soluble Si was lacking (Figure 5b-d).

Analytical techniques, such as XRD, FTIR and SEM, were used in order to characterize the final products. Figure 6; Figure 7 show the XRD patterns and the FTIR spectra of samples corresponding to different experiments of synthesis optimization. The grouping of each diagram was done according 
to the $\mathrm{R} / \mathrm{Al}$ and $\mathrm{Si} / \mathrm{Al}$ ratios. As stated before, these factors make the highest contributions to the development of the compressive strength.

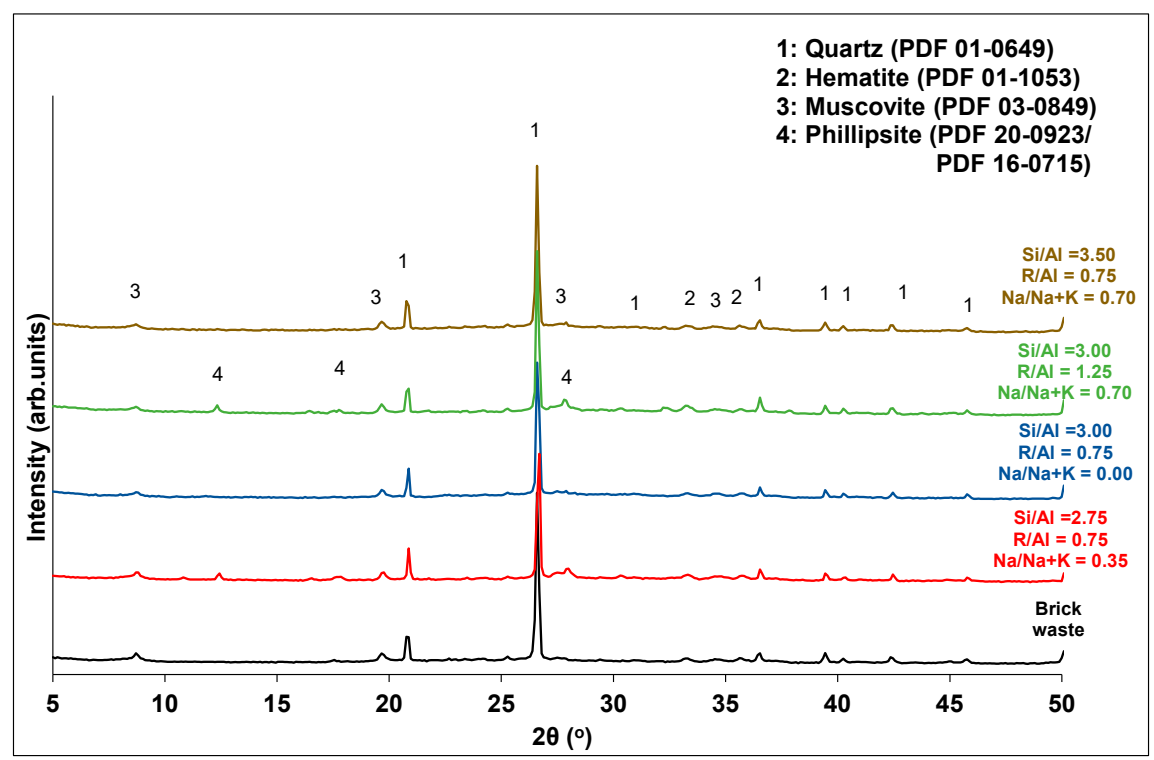

Figure 6. XRD patterns of brick precursor and selected geopolymer samples.

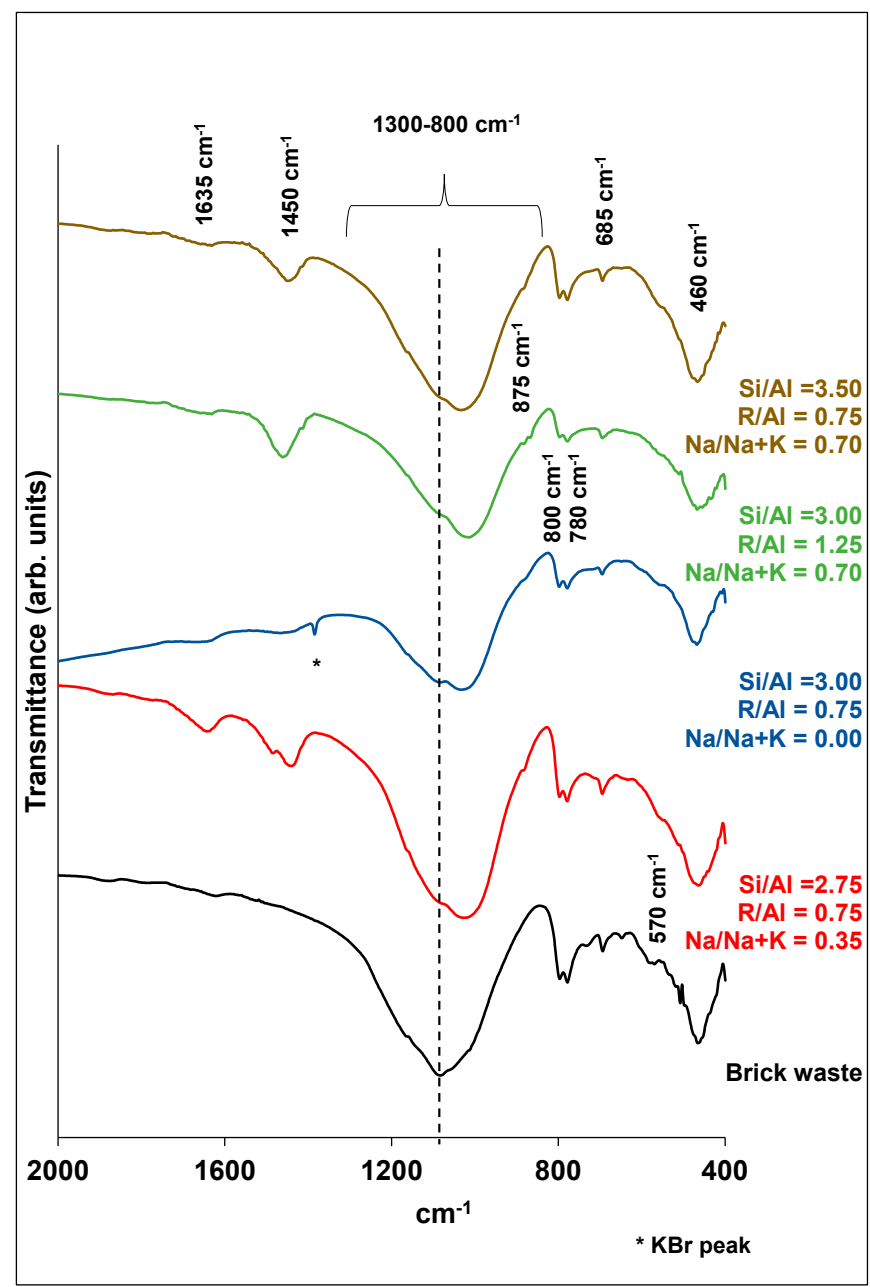

Figure 7. FTIR spectra of brick precursor and selected brick geopolymers. 
Concerning the XRD analysis (Figure 6), all products contain the mineral phases of the brick precursor (quartz, muscovite and hematite). The absence of soluble silicon ( $\mathrm{Si} / \mathrm{Al}=2.75$ ) or the high alkali content $(\mathrm{R} / \mathrm{Al}=1.25)$ in the activation solution favors the formation of zeolites (phillipsite) that downgrade the mechanical performance of the products. The relationship between low soluble silicon content or high alkali content and the formation of zeolites in geopolymers has also been reported in the literature $[42,43]$. The alkali type modifies the stoichiometry of the formed zeolites. In particular, high potassium content favors the formation of the phillipsite K, syn (PDF 16-0715). The increase in sodium content favors the formation of a mixed phillipsite with chemical formula $\mathrm{KNaCaFeAlSiO}_{6} \cdot 39 \mathrm{H}_{2} \mathrm{O}$ (PDF 20-0923).

The FTIR spectrum of the brick precursor is mainly characterized by the presence of a broad absorption peak in the range $800-1300 \mathrm{~cm}^{-1}$ (Figure 7). This absorption is attributed to the asymmetric stretching vibrations of Si-O-Si and/or Si-O-Al bonds, while the lack of sharpness is indicative of the glassy and heterogeneous nature of brick waste. The shift of this absorption peak to smaller wavenumbers, in the case of geopolymers, indicates an increased substitution of Si by tetrahedral Al. The above changes are consistent with the formation of an aluminosilicate network in the polymeric structures $[16,35,42,44,45]$.

The vibrations at $\sim 1400 \mathrm{~cm}^{-1}$ are characteristic of the $\left[\mathrm{CO}_{3}\right]^{2-}$ ions, indicating carbonization. This peak is absent in the case of the brick precursor. The absorbance at $875 \mathrm{~cm}^{-1}$ is related to symmetric stretching vibrations of Al-O, and it constitutes a sign of geopolymerization [35]. As for the 800, 780 and $685 \mathrm{~cm}^{-1}$ peaks, these are connected with the symmetric stretching vibrations of Si-O-T bonds. As the $\mathrm{Si} / \mathrm{Al}$ ratio increases, the latter band shifts to higher wavenumbers in relation to the brick waste, showing the enrichment of the alumino-silicate network in silicon [35,42]. The band at $570 \mathrm{~cm}^{-1}$ is assigned to the $\mathrm{Fe}-\mathrm{O}$ bond vibrations of hematite [46], which is present in the brick precursor. Finally, the absorption peak at $\sim 460 \mathrm{~cm}^{-1}$ corresponds to the O-Si-O asymmetric bending vibrations, which do not show any changes in the case of geopolymer products. In general, the bending vibrations are not sensitive to changes in the form of the aluminosilicate network [35,47].

Figure 8 shows SEM micrographs of different magnifications, and the phase stoichiometry of the geopolymer prepared under the optimum conditions of synthesis $(\mathrm{Si} / \mathrm{Al}=3.00, \mathrm{R} / \mathrm{Al}=0.75$ and $\mathrm{Na} / \mathrm{Na}$ $+\mathrm{K}=0.35$ ). The products consist of unreacted grains surrounded by a homogenous and compact binding matrix. The polygonal grains (size: $10-20 \mu \mathrm{m}$ ) are mainly quartz, as is confirmed by EDS analysis. These grains act as microaggregates and enhance the strength of the specimens. These photos are from the sample with the highest strength, so it is assumed that the binding matrix is mainly a geopolymeric matrix. EDS analysis at different points of this matrix showed that its stoichiometry is Si:Al:R = 24.6:5.6:13.5 $(\mathrm{R}=\mathrm{Na}+\mathrm{K})$.

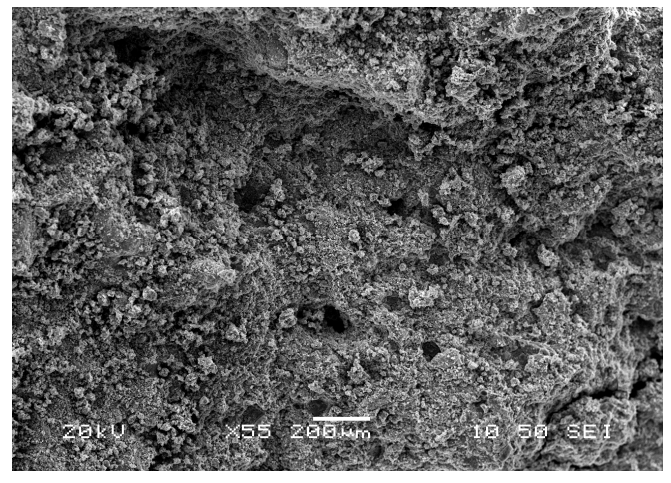

(a)

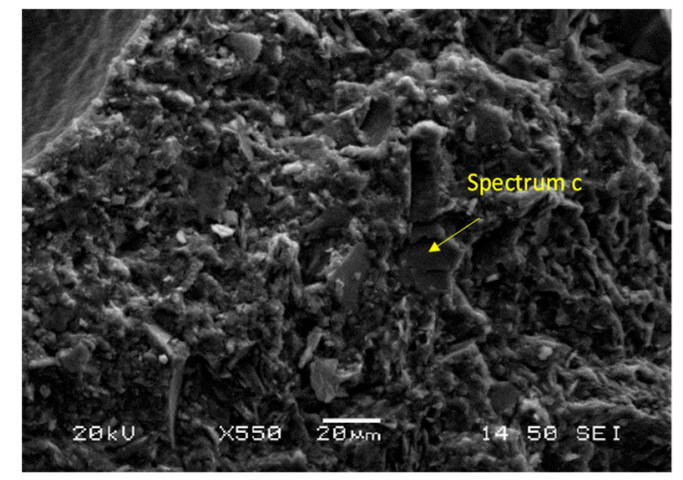

(b)

Figure 8. Cont. 


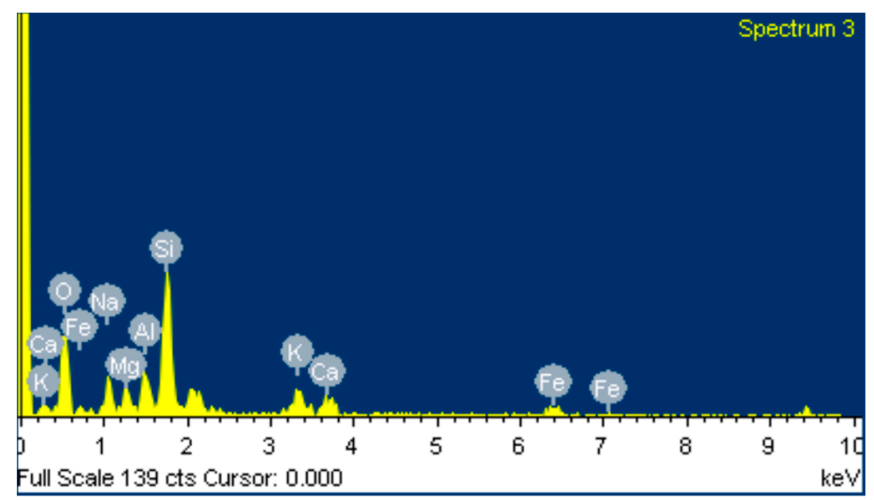

(c)

Figure 8. SEM micrographs of the optimum geopolymer synthesis (a,b) along with EDS analysis (c).

\subsection{Glass Waste Dissolution}

Table 6 presents the $\mathrm{Si}$ and $\mathrm{Na}$ contents in the liquid products $(\mathrm{mg} / 250 \mathrm{~mL})$, the $\mathrm{SiO}_{2} / \mathrm{Na}_{2} \mathrm{O}$ molar ratio of the liquid products as well as the conversion yield of $\mathrm{SiO}_{2}$.

Table 6. Composition of the liquid product coming from glass dissolution.

\begin{tabular}{ccccc}
\hline Sample & $\begin{array}{c}\mathbf{S i} \\
(\mathbf{m g} / \mathbf{2 5 0} \mathbf{~ m L})\end{array}$ & $\begin{array}{c}\mathbf{N a} \\
(\mathbf{m g} / \mathbf{2 5 0} \mathbf{~ m L})\end{array}$ & $\mathbf{S i O}_{\mathbf{2}} / \mathbf{N a}_{\mathbf{2}} \mathbf{O}$ & Yield (\%) \\
\hline GL1 & 1467.5 & $10,925.0$ & 0.22 & $43 \%$ \\
GL2 & 1979.6 & 8629.8 & 0.38 & $58 \%$ \\
GL3 & 2480.0 & 5922.5 & 0.69 & $72 \%$ \\
GL4 & 1123.6 & 3303.7 & 0.56 & $33 \%$ \\
GL5 & 894.4 & 6208.7 & 0.24 & $10 \%$ \\
GL6 & 1348.3 & 3513.8 & 0.63 & $39 \%$ \\
\hline
\end{tabular}

As shown in Table 6, the increase of the dissolution temperature from $100{ }^{\circ} \mathrm{C}$ (GL1) to $150{ }^{\circ} \mathrm{C}$ (GL2) increases the glass conversion by $15 \%$. An increase in yield of $6 \%$ is also observed when the dissolution time increases from $24 \mathrm{~h}$ (GL4) to $96 \mathrm{~h}$ (GL6). Nevertheless, the effect of the dissolution temperature is at least two times greater than that of the dissolution time. This is possibly attributed to the fact that the experiments with varied dissolution times were performed in extracting solutions with low $\mathrm{NaOH}$ content. In general, intense dissolution conditions (temperature, time) help the depolymerization and destruction of the glass network, and therefore its gradual dissolution.

The introduction of sodium hydroxide amounts into the extracting solution $\left(\mathrm{NaOH} / \mathrm{SiO}_{2}\right)$ is beneficial to the glass dissolution, since the increase of $\mathrm{NaOH} / \mathrm{SiO}_{2}$ from 1 (GL4) to 2 (GL3) led to an enhancement of conversion yield by about 39\%. The extraction mechanism of $\mathrm{SiO}_{2}$ from the glass network in alkaline media is governed by a hydrolysis reaction of $\mathrm{OH}$ - groups and $\mathrm{Si}-\mathrm{O}-\mathrm{Si}$ bonds, and it is $\mathrm{pH}$-dependent [25-29]. However, more concentrated extracting solutions $\left(\mathrm{NaOH} / \mathrm{SiO}_{2}=4\right)$ inhibited the dissolution of $\mathrm{Si}$. In the literature, it is reported that when a critical amount of $\mathrm{NaOH}$ solution is reached, the rate of reaction becomes constant [48,49]. Nevertheless, the $\mathrm{NaOH}$ concentration $(1 \mathrm{M})$ of such solutions is much lower than that used in GL2 $(10 \mathrm{M})$. It seems that the high concentration of -OH groups available in this system disrupts the equilibrium of the hydrolysis reaction. This fact is supported by the XRD analysis showing that higher amounts of calcium silicate and quartz phases are precipitated in GL2.

Denser extracting solutions were also tested, to see how the amount of water $\left(\mathrm{H}_{2} \mathrm{O} / \mathrm{SiO}_{2}\right)$ affects the glass dissolution. As was expected, the reduction of $\mathrm{H}_{2} \mathrm{O} / \mathrm{SiO}_{2}$ 's molar ratio to 9 (GL5) from 23 (GL6) had a negative effect, since the water, apart from playing the role of the diluent of the sodium hydroxide, supplies the system with $\mathrm{H}^{+}$ions, which react with $\mathrm{Si}-\mathrm{O}$ - and enhance the destruction of the glass network. 
More or less the same trend was followed for the $\mathrm{SiO}_{2} / \mathrm{Na}_{2} \mathrm{O}$ ratio of the produced sodium silicate solutions. Intense extracting conditions $\left(\mathrm{T}=150^{\circ} \mathrm{C}, \mathrm{t}=96 \mathrm{~h}\right)$ and diluted starting solutions $\left(\mathrm{H}_{2} \mathrm{O} / \mathrm{SiO}_{2}=23\right)$ led to sodium silicate solutions with higher values of $\mathrm{SiO}_{2} / \mathrm{Na}_{2} \mathrm{O}$ ratio. Concerning sodium hydroxide content, the highest $\mathrm{SiO}_{2} / \mathrm{Na}_{2} \mathrm{O}$ ratio was achieved for $\mathrm{NaOH} / \mathrm{SiO}_{2}=2$ (GL3). As mentioned before, this ratio value maximizes the dissolution of silica from glass waste. Higher values of $\mathrm{NaOH} / \mathrm{SiO}_{2}(=4)$ led to decreased $\mathrm{SiO}_{2} / \mathrm{Na}_{2} \mathrm{O}$ ratio values, since the sodium ion content in the extracting solution is significantly high.

The parameters that maximized glass waste dissolution are the following: $\mathrm{NaOH} / \mathrm{SiO}_{2}=2$, $\mathrm{H}_{2} \mathrm{O} / \mathrm{SiO}_{2}=23, \mathrm{~T}=150{ }^{\circ} \mathrm{C}$ and $\mathrm{t}=24 \mathrm{~h}$ (GL2 sample). In particular, $72 \%$ of the solid $\mathrm{SiO}_{2}$ in the waste glass was dissolved. The resulting liquid phase is a sodium silicate-rich aqueous product with a $\mathrm{SiO}_{2} / \mathrm{Na}_{2} \mathrm{O}$ molar ratio close to 0.7 . This value is very close to the molar ratio of $\mathrm{SiO}_{2}$ to $\mathrm{Na}_{2} \mathrm{O}(0.68)$ in the activation solution of the CDW brick-based geopolymer preparation.

The solid residues of the glass treatment were characterized by XRD (Figure 9). In all cases, the residues contain a mixture of calcium silicates and quartz from unreacted glass particles. When the sodium hydroxide content increases, the peak intensities of the quartz phase gradually decrease, revealing its partial decomposition. In the case of GL3, the quartz phase appears to have been almost completely consumed, while extra calcium silicate phases containing sodium are still present. A further increase in sodium hydroxide content (GL2) leads to solid products that are more crystallized, with small amounts of quartz still visible. This observation may explain the decrease in the silicon conversion yield of GL2.

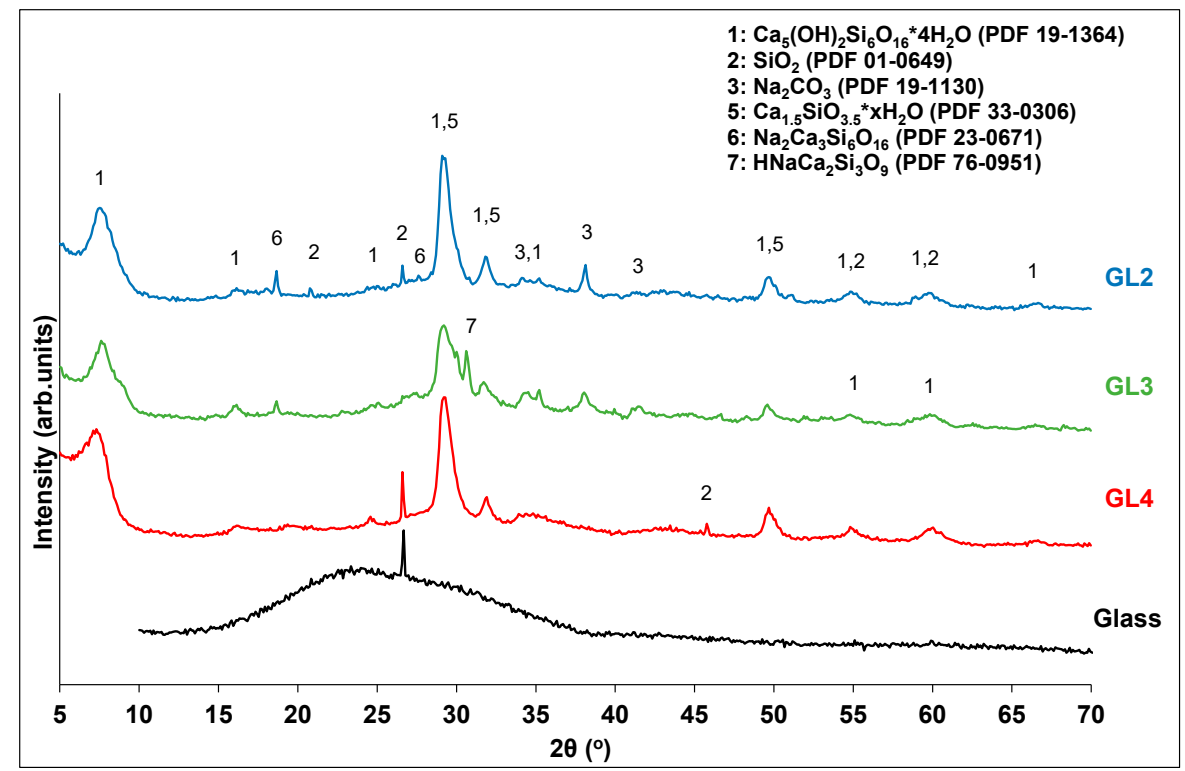

Figure 9. XRD analysis of glass waste and selected solid residues.

\subsection{Preparation of Geopolymers Using Glass Waste Activators}

The glass waste solutions GL3 and GL6 have $\mathrm{Si}_{2} \mathrm{O} / \mathrm{Na}_{2} \mathrm{O}$ ratios close to that of the activation solution used for the optimum geopolymeric synthesis (0.68), and they were further tested as activators. The GL2 solution was also tested, as it exhibits a high silica yield. Prior to use, a condensation process of the glass waste solutions took place in order to evaporate excess water and achieve the same solid/liquid ratio in the precursor mixture. The applied synthesis factors and curing conditions were based on the optimum synthesis prepared with the conventional activation solution $(\mathrm{R} / \mathrm{Al}=0.75$, $\mathrm{Na} / \mathrm{Na}+\mathrm{K}=1, \mathrm{~T}=80{ }^{\circ} \mathrm{C}$ and $\mathrm{t}=3 \mathrm{~d}$ ).

Figure 10 presents the compressive strength of the produced geopolymers using either the conventional activation solution (GEO_REF) or glass waste solutions. It is obvious that the use of the GL3 solution in the preparation of geopolymeric samples achieves a similar mechanical performance 
to that of the reference synthesis. On the contrary, the GL6 solution leads to geopolymers with reduced mechanical strengths. The low conversion yield of GL6 results in lower Si and Na contents than those required for the geopolymer synthesis. In a similar manner, the GL2-based product possesses degraded compressive strength values, since its Si content is considerably lower than needed. In all cases, geopolymers with compressive strength values higher than $10 \mathrm{MPa}$ were prepared. The robustness of the produced geopolymers is also indicated by the density values (Figure 10). Specimens with high mechanical strength are coupled with high density, and vice versa.

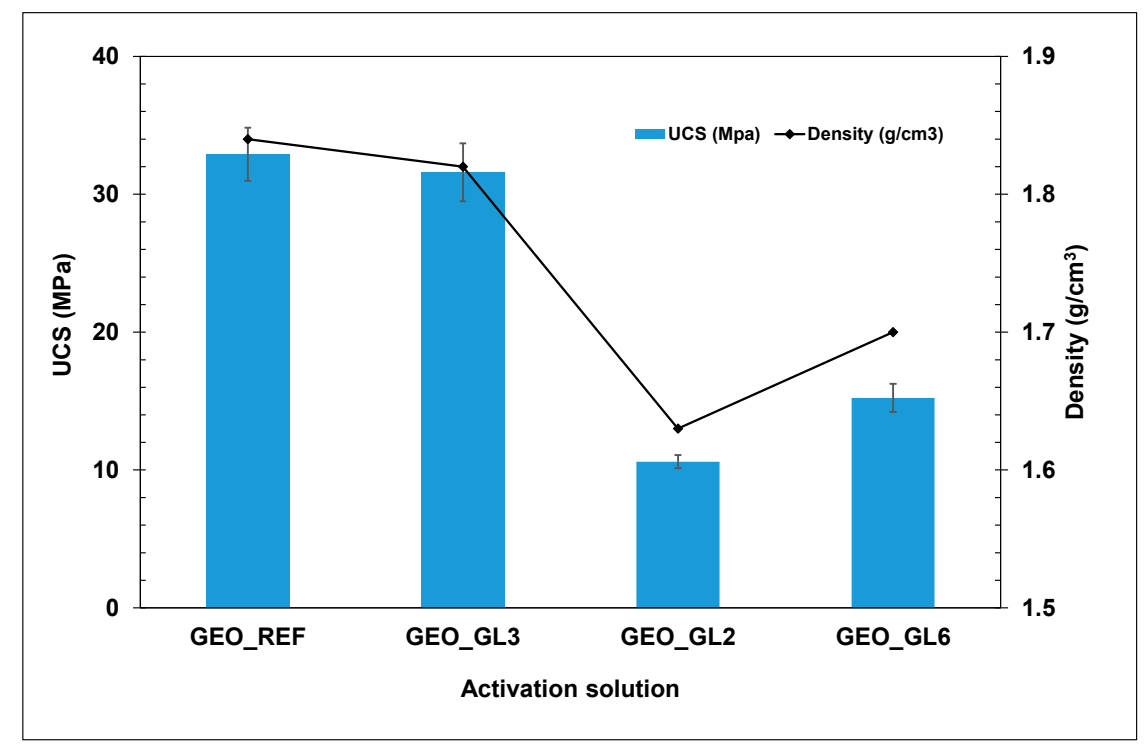

Figure 10. Mechanical performance of the produced geopolymers with different activation solutions.

The reference geopolymer (CDW brick and conventional activation solution) has an $82 \% w / w$ CDW content in the solid precursors' base, and a content of $76 \% w / w$ in the final product. The joint exploitation of CDW brick and glass in geopolymer synthesis increases the CDW content to $91 \% w / w$ and $85 \% w / w$, in a solid precursors' base and in the final product, respectively.

\section{Conclusions}

This study suggests a way to maximize the valorization of construction and demolition wastes in geopolymer technology. CDW brick is used as the aluminosilicate precursor, while CDW glass is appropriately processed to obtain the activation solution. The geopolymer products contain as high as $91 \%$ CDWs (on solid precursors' base), in accordance with the demands of EU legislation and the principles of the circular economy. The following conclusions can be drawn:

- $\quad$ CDW brick can be successfully reused in the production of green building materials, since products with a wide range of compressive strength values were obtained (20.3-43.7 MPa). The geopolymer synthesis was efficiently optimized by the application of the Taguchi method, a fractional multifactorial design methodology;

- The silicon and alkali contents in the activation solution greatly affect the performance of the brick-based geopolymers. Very low or high amounts of these species are responsible for the formation of extra phases, such as zeolites and carbonates that degrade the mechanical performance of the products;

- $\quad$ CDW glass can be effectively processed and then used as an activator for geopolymer synthesis. The treatment of glass waste at $150{ }^{\circ} \mathrm{C}$, for $24 \mathrm{~h}$, in an alkaline solution with molar ratios $\mathrm{NaOH} / \mathrm{SiO}_{2}=2$ and $\mathrm{H}_{2} \mathrm{O} / \mathrm{SiO}_{2}=23$, leads to $72 \%$ silica yield;

- Glass waste solutions can effectively substitute conventional activators based on commercial chemicals, as in both cases the final products have the same compressive strength (32 MPa). 
A study on the development of a solid activator based on glass waste for the preparation of one-part geopolymer mixtures will be the next step in this research. In this case, the corrosive reagents needed for the preparation of the traditional liquid activators will be replaced by low-cost, solid activators, originating from CDWs. One-part synthesis will be simpler, safer and more practical, since the aluminosilicate precursor is premixed with the solid activator, and then just with water, in a process very similar to that of Portland cement-based materials.

Author Contributions: Conceptualization, D.K., A.S., G.K., S.T.; methodology, D.K., A.S.; resources, A.S.; writing—original draft preparation, D.K.; writing—review and editing, S.T., G.K.; project administration, S.T. and G.K.; funding acquisition, G.K. All authors have read and agreed to the published version of the manuscript.

Funding: This research work was funded by the European Union Horizon 2020 (H2020-EEB-2016-2017, “Green Integrated Structural Elements for Retrofitting and New Construction of Buildings-GreenINSTRUCT", Grant No.: 723825).

Acknowledgments: The authors gratefully acknowledge L. Isufai and A. Karamperi for their valuable assistance in performing experiments on geopolymer synthesis, XRF and ICP-OES measurements.

Conflicts of Interest: The authors declare no conflict of interest.

\section{References}

1. Ellen MacArthur Foundation. Towards the Circular Economy: An Economic and Business Rationale for an Accelerated Transition; Ellen MacArthur Foundation: Cowes, UK, 2012; pp. 21-34.

2. Geissdoerfer, M.; Savaget, P.; Bocken, N.M.P.; Hultink, E.J. The circular economy-A new sustainability paradigm? J. Clean. Prod. 2017, 143, 757-768. [CrossRef]

3. Murray, A.; Skene, K.; Haynes, K. The circular economy: An interdisciplinary exploration of the concept and application in a global context. J. Bus. Ethics 2017, 140, 369-380. [CrossRef]

4. PBL Netherlands Environmental Assessment Agency. Trends in Global $\mathrm{CO}_{2}$ Emissions: 2016 Report; PBL Netherlands Environmental Assessment Agency: Hague, The Netherlands, 2016.

5. Huntizinger, D.N.; Eatmon, T.D. A life-cycle assessment of Portland cement manufacturing: Comparing the traditional process with alternative technologies. J. Clean. Prod. 2009, 17, 668-675. [CrossRef]

6. Andrew, R.M. Global $\mathrm{CO}_{2}$ emissions from cement production. Earth Syst. Sci. Data 2019, 11, 1675-1710. [CrossRef]

7. Purdon, A.O. The action of alkalis on blast-furnace slag. J. Soc. Chem. Ind. 1940, 59, 191-202.

8. Glukhovsky, V.D.; Zaitsev, Y.; Pakhomow, V. Slag-alkaline cements and concretes structures, properties, technological and economic aspects of the use. Silic. Ind. 1983, 10, 197-200.

9. Davidovits, J. Geopolymers and geopolymeric materials. J. Therm. Anal. 1989, 35, 429-441. [CrossRef]

10. Van Jaarsveld, J.G.S.; Van Deventer, J.S.J.; Lorenzen, L. Factors affecting the immobilization of metals in geopolymerized fly ash. Metall. Mater. Trans. B 1998, 29, 283-291. [CrossRef]

11. Provis, J.L.; van Deventer, J.S.J. Geopolymers: Structures, Processing, Properties and Industrial Applications, 1st ed.; Woodhead Publishing: Cambridge, UK, 2009.

12. Davidovits, J. Geopolymer Chemistry and Applications, 2nd ed.; Institut Geopolymere: Saint-Quentin, France, 2008; pp. 3-12.

13. Eurostat Statistics Explained. Available online: https://ec.europa.eu/eurostat/statistics-explained/index.php/ Waste_statistics\#Total_waste_generation (accessed on 25 March 2020).

14. Directive 2008/98/EC of the European Parliament and of the Council on Waste and Repealing Certain Directives; O J 312; European Union: Brussels, Belgium, 2008; pp. 3-30.

15. De Rossi, A.; Ribeiro, M.J.; Labrincha, J.A.; Novais, R.M.; Hotza, D.; Moreira, R.F.P.M. Effect of the particle size range of construction and demolition waste on the fresh and hardened-state properties of fly ash-based geopolymer mortars with total replacement of sand. Process Saf. Environ. 2019, 129, 130-137. [CrossRef]

16. Komnitsas, K.; Zaharaki, D.; Vlachou, A.; Bartzas, G.; Galetakis, M. Effect of synthesis parameters on the quality of construction and demolition wastes (CDW) geopolymers. Adv. Powder Technol. 2015, 26, 368-376. [CrossRef]

17. Soultana, A.; Valouma, A.; Bartzas, G.; Komnitsas, K. Properties of inorganic polymers produced from brick waste and metallurgical slag. Minerals 2019, 9, 551. [CrossRef] 
18. Guo, X.; Shi, H.; Wei, X. Pore properties, inner chemical environment, and microstructure of nano-modified CFA-WBP (class C fly ash-waste brick powder) based geopolymers. Cem. Concr. Comp. 2017, 79, 53-61. [CrossRef]

19. Dadsetan, S.; Siad, H.; Lachemi, M.; Sahmaran, M. Construction and demolition waste in geopolymer concrete technology: A review. Mag. Concr. Res. 2019, 71, 1232-1252. [CrossRef]

20. Burciaga-Díaz, O.; Durón-Sifuentes, M.; Díaz-Guillén, J.A.; Escalante-García, J.I. Effect of waste glass incorporation on the properties of geopolymers formulated with low purity metakaolin. Cem. Concr. Comp. 2020, 107, 103492. [CrossRef]

21. Torres-Carrasco, M.; Puertas, F. Waste glass in the geopolymer preparation. Mechanical and microstructural characterization. J. Clean. Prod. 2015, 90,397-408. [CrossRef]

22. Samadi, M.; Shah, K.W.; Huseien, G.F.; Lim, N.H.A.S. Influence of glass silica waste nano powder on the mechanical and microstructure properties of alkali-activated mortars. Nanomaterials 2020, 10, 324. [CrossRef] [PubMed]

23. Vinai, R.; Soutsos, M. Production of sodium silicate powder from waste glass cullet for alkali activation of alternative binders. Cem. Concr. Res. 2019, 116, 45-56. [CrossRef]

24. Xiao, R.; Ma, Y.; Jiang, X.; Zhang, M.; Zhang, Y.; Wang, Y.; Huang, B.; He, Q. Strength, microstructure, efflorescence behavior and environmental impacts of waste glass geopolymers cured at ambient temperature. J. Clean. Prod. 2020, 252, 119610. [CrossRef]

25. Brykov, A.S.; Korneev, V.I. Production and usage of powdered alkali metal silicate hydrates. Metallurgist 2009, 52, 648-652. [CrossRef]

26. El-Shamy, T.M.; Panteno, C.G. Decomposition of silicate glasses in alkaline solutions. Nature 1977, 266, 704-706. [CrossRef]

27. El-Shamy, T.M.; Lewis, J.; Douglas, R.W. The dependence on the $\mathrm{pH}$ of the decomposition of glasses by aqueous solutions. Glass Technol. 1972, 13, 81-87.

28. Niibori, Y.; Kunita, M.; Tochiyama, O.; Chida, T. Dissolution rates of amorphous silica in highly alkaline solution. J. Nucl. Sci. Technol. 2000, 37, 349-357. [CrossRef]

29. Paul, A. Chemical durability of glasses; a thermodynamic approach. J. Mater. Sci. 1977, 12, $2246-2268$. [CrossRef]

30. Taguchi, G.; Konishi, S. Taguchi Methods, Orthogonal Arrays and Linear Graphs, Tools for Quality American Supplier Institute, 1st ed.; American Supplier Institute: Dearborn, MI, USA, 1987; pp. 8-35.

31. Ken, P.W.; Ramli, M.; Ban, C.C. An overview on the influence of various factors on the properties of geopolymer concrete derived from industrial by-products. Constr. Build. Mater. 2015, 77, 370-395.

32. Zhang, P.; Wang, K.; Li, Q.; Wang, J.; Ling, Y. Fabrication and engineering properties of concretes based on geopolymers/alkali-activated binders-A review. J. Clean. Prod. 2020, 258, 120896. [CrossRef]

33. Panagiotopoulou, C.; Tsivilis, S.; Kakali, G. Application of the Taguchi approach for the composition optimization of alkali activated fly ash binders. Constr. Build. Mater. 2015, 91, 17-22. [CrossRef]

34. Kioupis, D.; Tsivilis, S.; Kakali, G. Development of green building materials through alkali activation of industrial wastes and by-products. Mater. Today Proc. 2018, 5, 27329-27336. [CrossRef]

35. Kioupis, D.; Kavakakis, C.; Tsivilis, S.; Kakali, G. Synthesis and Characterization of Porous Fly Ash-Based Geopolymers Using Si as Foaming Agent. Adv. Mater. Sci. Eng. 2018, 2018, 1-11. [CrossRef]

36. Keawthun, M.; Krachodnok, S.; Chaisena, A. Conversion of waste glasses into sodium silicate solutions. Int. J. Chem. Sci. 2014, 12, 83-91.

37. Foletto, E.L.; Gratieri, E.; Hadlich de Oliveira, L.; Jahn, S.L. Conversion of Rice Hull Ash into Soluble Sodium Silicate. Mater. Res. 2006, 9, 335-338. [CrossRef]

38. Asprogerakas, A.; Koutelia, A.; Kakali, G.; Tsivilis, S. Durability of fly ash geopolymer mortars in corrosive environments, compared to that of cement mortars. Adv. Sci. Tech. 2014, 92, 84-89.

39. Duxson, P.; Mallicoat, S.W.; Lukey, G.C.; Kriven, W.M.; van Deventer, J.S.J. The effect of alkali and Si/Al ratio on the development of mechanical properties of metakaolin-based geopolymers. Coll. Surf. A Physicochem. Eng. Asp. 2007, 292, 8-20. [CrossRef]

40. Xu, H.; Van Deventer, J.S.J. The geopolymerisation of aluminosilicate materials. Int. J. Miner. Process. 2000, 59, 247-258. [CrossRef]

41. Criado, M.; Palomo, A.; Fernandez-Jimenez, A. Alkali activation of fly ashes. Part I: Effect of curing conditions on the carbonation of the reaction products. Fuel 2005, 84, 2048-2054. [CrossRef] 
42. Bakharev, T. Geopolymeric materials prepared using Class F fly ash and elevated temperature curing. Cem. Concr. Res. 2005, 35, 1224-1232. [CrossRef]

43. Silva, P.D.; Crenstil, K.S. Medium-term phase stability of $\mathrm{Na}_{2} \mathrm{O}-\mathrm{Al}_{2} \mathrm{O}_{3}-\mathrm{SiO}_{2}-\mathrm{H}_{2} \mathrm{O}$ geopolymer systems. Cem. Concr. Res. 2007, 38, 870-876. [CrossRef]

44. Rees, C.A.; Provis, J.L.; Lukey, G.C.; van Deventer, J.S.J. Attenuated Total Reflectance Fourier Transform Infrared Analysis of Fly Ash Geopolymer Gel Aging. Langmuir 2007, 23, 8170-8179. [CrossRef]

45. Nenadović, S.S.; Kljajević, L.M.; Nešić, M.A.; Petković, M.Z.; Trivunac, K.V.; Pavlović, V.B. Structure analysis of geopolymers synthesized from clay originated from Serbia. Environ. Earth Sci. 2017, 76, 1-10. [CrossRef]

46. Sheikh, M.R.; Gohain Barua, A. X-ray diffraction and fourier transform infrared spectra of the bricks of the Kamakhya temple. Indian J. Pure Appl. Phys. 2013, 51, 745-748.

47. Backarev, T. Resistance of geopolymer materials to acid attack. Cem. Concr. Res. 2005, 35, 658-670. [CrossRef]

48. Goyal, S.K.; Cutler, I.B. Absorption of water in waste glass as a precursor for foam formation. J. Non Cryst. Solids 1975, 19, 311-320. [CrossRef]

49. Kalapathy, U.; Proctor, A.; Shultz, J. A simple method for production of pure silica from rice hull ash. Bioresour. Technol. 2000, 73, 257-262. [CrossRef]

(C) 2020 by the authors. Licensee MDPI, Basel, Switzerland. This article is an open access article distributed under the terms and conditions of the Creative Commons Attribution (CC BY) license (http://creativecommons.org/licenses/by/4.0/). 